\title{
How eukaryotic filamentous pathogens evade plant recognition
}

\author{
Ely Oliveira-Garcia ${ }^{1}$ and Barbara Valent ${ }^{1}$ \\ ${ }^{1}$ Kansas State University, Department of Plant Pathology, 4024 Throckmorton Plant Sciences \\ Center, Manhattan, KS 66506-5502, USA. \\ Corresponding author: Barbara Valent (bvalent@ksu.edu)
}

\begin{abstract}
Plant pathogenic fungi and oomycetes employ sophisticated mechanisms for evading host recognition. After host penetration, many fungi and oomycetes establish a biotrophic interaction. It is assumed that different strategies employed by these pathogens to avoid triggering host defence responses, including establishment of biotrophic interfacial layers between the pathogen and host, masking of invading hyphae and active suppression of host defence mechanisms, are essential for a biotrophic parasitic lifestyle. During the infection process, filamentous plant pathogens secrete various effectors, which are hypothesized to be involved in facilitating effective host infection. Live-cell imaging of fungi and oomycetes secreting fluorescentlylabelled effector proteins and functional characterization of the components of biotrophic interfaces have led to recent progress in understanding how eukaryotic filamentous pathogens evade plant recognition.
\end{abstract}

\section{Introduction}

Eukaryotic filamentous plant pathogens, e.g., fungi and oomycetes, cause extensive losses to annual yields of main agricultural crops worldwide $[1,2]$. In order to control these plant diseases, the broad spectrum of mechanisms that filamentous pathogens use to colonize host plants needs 
to be elucidated. The first layer of the plant immune system involves basal defence responses that are triggered by the detection of pathogen-associated molecular patterns (PAMPs, e.g., chitin, glucan, ergosterol, flagelin). PAMP-triggered immunity (PTI) involves plant pattern recognition receptors (PRRs, e.g., chitin, glucan, ergosterol recognition receptors), which are extracellular transmembrane receptor proteins in the host-pathogen interface. A second layer of defence involves recognition of specific avirulence (AVR)-effectors secreted by the pathogen to promote infection. AVR-effector recognition generally occurs through cytoplasmic NB-LRRtype immune receptors leading to effector-triggered immunity in the classical gene-for-gene interaction $\left[3^{*}, 4,5\right]$. Evasion of plant recognition seems to be a challenge for filamentous pathogens, considering that both PAMPs and plant PRRs are broadly conserved [3*] and the recognition mechanism of diverse AVR-proteins by respective NB-LRR-receptors is highly efficient [6]. In this review, we focus on the cellular and molecular biology of biotrophic fungal and oomycete encounter sites and effectors secreted in plant tissue, and on the current understanding of the suppression of plant recognition and modulation of plant metabolism for the pathogen's own benefit.

\section{The challenging road to evade plant recognition}

A successful eukaryotic pathogen must accomplish several tasks during infection of a host plant. After host invasion, many important filamentous plant pathogens establish a biotrophic interaction, which depends on living host cells [2,7]. The challenges for biotrophic pathogens are to invade the host tissue with minimal damage and to evade recognition by plant cells. In order to accomplish that, biotrophic pathogens developed a range of sophisticated strategies. Here we 
highlight three major strategies: (i) establishment of carbohydrate-rich and protein-containing interfacial layers that separate fungal cell walls and plant plasma membrane; (ii) effector modulation of host metabolism and suppression of plant defences (iii) remodelling of the pathogen cell wall for evasion of PAMP-triggered immunity.

\section{$1^{\text {st }}$ Strategy: Establishing a unique interface with the host plant cell}

In order to achieve their challenges, many biotrophic pathogens develop highly-specialized intracellular feeding structures (Figure 1), which are surrounded by the plant plasma membrane (the extrahaustorial membrane (EHM) or the extrainvasive hyphal membrane (EIHM)) $\left[8,9^{* *}\right]$. Importantly, this interface between the pathogen cell wall and plant membrane is called the extrahaustorial matrix (EHMx) (Figure 1a, light green interface), or the extrainvasive hyphal matrix (EIHMx, Figure 1b), and it plays an essential role in maintaining the biotrophic lifestyle, including nutrient acquisition and evasion of plant recognition [10,11]. The EHMx is a gelmatrix enriched in carbohydrates and proteins from both the fungus and the host $\left[9^{* *}, 12,13\right]$. Highly specialized plant sugar transporters, SWEET (hexose and sucrose transporters), are induced during biotrophic invasion by a powdery mildew fungus, suggesting they are involved in delivering nutrients into the EHMx [14]*. Plasma membranes from biotrophic pathogens contain in planta-expressed sugar and amino acid transporters as well as $\mathrm{H}+\mathrm{ATPases}$, allowing nutrient uptake $[15,16]$. Notably, this is mechanistically essential, since sugars released by pathogen activity trigger plant defence responses [17]. A classic example is the sucrose $/ \mathrm{H}+$-symporter (Srt1) from Ustilago maydis [18], in which knockout mutations strongly affect the pathogen's virulence. Srt1 has been demonstrated to have an unusually high substrate affinity required for 
providing the pathogen with efficient carbon supply, while minimizing apoplastic signals that trigger plant defence responses [18,19].

Remarkably, strategic establishment of a unique, individualized environment during biotrophic development is a key characteristic of different filamentous biotrophic pathogens that is independent of their ability to differentiate specialized infection structures and of their plant colonization styles (intercellular growth, e.g., Cladosporium fulvum [20] or subcuticular growth, e.g., Venturia inequalis [21]). Moreover, genome-wide transcriptome analysis (e.g., microarray analysis [16] and Deep Illumina RNA sequencing [22**,23] of biotrophic pathogens at different infection stages) clearly confirms the hypothesis that the fungal secreted proteome is reprogrammed to be perfectly in-line with the needs of a biotroph. Indeed, several pathogen extracellular lytic-enzymes are suppressed in the EHMx and they are less abundant in the proteomes of biotrophic species [23,24,25,26]. By contrast, multiple effectors are secreted into the EHMx, in order to modulate metabolism and evade plant recognition [23] (Table1). Fungal effectors will be described in detail in the next section.

\section{$2^{\text {nd }}$ Strategy: Secreting highly specialized effectors}

The ability to manipulate and reprogram host metabolism is a hallmark of biotrophic plant pathogens [27,28]. In this context, effector secretion in planta is a key feature for these pathogens. In general, effectors can be classified as small secreted proteins that often lack similarity to known proteins and are specifically expressed during biotrophic development, while remaining suppressed in vitro and during other developmental stages, e.g., the necrotrophic phase $[29,30]$. Early perception of plant signals is necessary to trigger transcription of effector- 
coding genes during plant infection [31**]. Effectors are also classified by their destinations in the interaction court, with apoplastic effectors residing in the extracellular plant compartment and cytoplasmic effectors translocating into the cytoplasm of living plant cells [32**] (Figure 2). Remarkably, cytoplasmic effectors of Magnaporthe oryzae are secreted by a distinct, golgiindependent secretion system into a specific EIHMx region called the biotrophic interfacial complex (BIC) (Figure 1 and 2, Gradient yellow-red structure on the bulbous hyphae) $\left[32^{* *}, 33^{*}, 34\right]$. Several $M$. oryzae effectors are translocated to the cytoplasm of rice cells and even move to non-infected neighboring cells, presumably to prepare them for future infection [34] (Figure 2a). As with candidate cytoplasmic effectors from diverse pathogens, putative effectors from the poplar rust, Melampsora larici-populina, were recently shown to accumulate in diverse plant cell compartments, presumably to reprogram biochemical events in host organelles [35**].

Many known effectors were identified as AVR effectors, which are recognized by plant resistance (R) immune receptor proteins and result in a hypersensitive resistance response that restricts pathogen growth and disease development $[29,36,4]$. However, effectors most likely evolved as virulence factors that provide benefits to the pathogen during host colonization. Therefore, effectors have been mentioned as both virulence factors and host-specificity factors, depending on whether they are known to confer a general benefit or to only promote growth in specific host plants [37]. Here we divide these effectors in major classes, according with their functions in the host plant.

Effectors targeting host lytic enzymes 
Host plants secrete, constitutively and in response to microbial attack, several lytic enzymes into their apoplastic compartments (also called extracellular or cell wall). The evolution of these pathogenesis-related (PR) plant lytic enzymes, such as proteases, glucanases and chitinases, led to specialization of pathogen effector proteins that inhibit these enzymes and protect the pathogen [38]. For example, effector GIP1 from the oomycete soybean pathogen Phytophthora sojae inhibits the soybean PR2 endoglucanase [39]. Importantly, proteins homologous to GIP1 were also found in the proteome of pathogenic fungi such as Fusarium oxyporum, Phaeosphaeria nodorum and Cochliobolus carbonum [39]. Although effectors that directly target chitinases have not yet been identified, effectors targeting apoplastic proteases have been identified in many pathogens. For instance, U. maydis secretes Pit2 that inhibits host cysteine proteases and is required for pathogenicity [40]. Additional examples of protease inhibitor-like effectors include Avr2 of C. fulvum, and EPIC1 and EPIC2B of P. infestans, which are active in the apoplast and are required for virulence [41,42]. The rust transferred protein 1 (RTP1) from the bean rust fungus Uromyces fabae shared similarity to cysteine protease inhibitors and it showed inhibition of yeast protease activity [26]. This effector was the first one shown to be translocated from haustoria into host cytoplasm, suggesting activity as a cytoplasmic effector [7]. Recently, Kemen and colleagues [43] reported that RTP1 forms multiple amyloid-like filaments extending into the host cytoplasm. The authors speculate a potential structural role of RTP1 in stabilizing haustoria inside host cells. Identification of RTP1 homologs in 13 rust fungal proteomes analyzed so far suggests this effector may play an important role in the rust lifestyle [26].

Effectors targeting immune response pathways 
Two effectors target the plant ubiquitination system, which plays an important role in regulation of plant immunity $[44,45,12]$. The AvrPiz-t effector from M. oryzae targets proteasome activity through interaction with the RING E3 ubiquitin ligase APIP6, leading to their mutual degradation and suppression of pathogen-associated molecular pattern-triggered immunity in rice [46] (Figure 2b). Another example is the AVR effector Avr3a from P. infestans, which binds and stabilizes a potato U-box E3 ubiquitin ligase CMPG1 blocking the Inf1-induced death of potato cells [44].

The cytoplasmic effector See1 (Seedling efficient effector1) of U. maydis is required for the reactivation of plant DNA synthesis in the nucleus, which is crucial for tumor progression in leaf cells $\left[47^{* *}\right]$. See1 interacts with a maize homolog of SGT1 (Suppressor of G2 allele of skp1), a factor acting in cell cycle progression in yeast (Saccharomyces cerevisiae) and an important component of plant and human innate immunity. These authors propose that See1 interferes with SGT1 activity, resulting in both modulation of immune responses and reactivation of DNA synthesis $\left[47^{* *}\right]$.

\section{Chitin-binding effectors}

Chitin, a $\beta$-1,4-linked homopolymer of $N$-acetyl-glucosamine (GlcNAc), is an essential fungal cell wall component. In tomato, sub-nanomolar concentrations of $\beta-1,4-N$-acetyl glucosamine oligomers are sufficient to induce defence responses [48]. Indeed, PAMPs such as chitin oligomers are recognized by corresponding plasma membrane-localized PRRs such as LysM receptors $\mathrm{CEBiP}$ and OsCERK1, which cooperatively mediate chitin elicitor signaling and immunity in rice [49]. In order to suppress chitin-triggered immunity, diverse pathogens secrete effectors that contain LysM amino acid domains (carbohydrate-binding modules that generally 
bind GlcNAc). These effectors either prevent the release of chitin oligosaccharides from fungal cell walls by plant chitinases or they sequester released oligosaccharides to prevent recognition (Figure 3). Chitin-binding effectors have been reported as essential for virulence in the fungal pathogens C. fulvum, Mycosphaerella graminicola and M. oryzae [50,51,52,53]. C. fulvum secretes Ecp6, a LysM effector that sequesters chitin oligosaccharides released from the fungal cell wall [50,51]. Another C. fulvum effector, Avr4, contains a different chitin-binding domain and functions as a plant chitinase inhibitor [50,51]. On the other hand, one of the three LysM effectors in the wheat intercellular pathogen $M$. graminicola has both wall protection and sequestering functions [52]. In M. oryzae, the LysM effector Slp1 binds chitin oligosaccharides and suppresses chitin-induced immunity mediated by the rice chitin elicitor binding PRR protein (CEBiP) [53] (Figure 3). Recent studies have shown that $N$-glycosylation of Slp1 is required to evade host innate immunity [54*].

\section{Peroxidase inhibitor-like effectors}

The Pep1 effector (Protein essential during penetration-1) from U. maydis protects fungal hyphae from the oxidative burst and reactive oxygen species (ROS) driven by peroxidases, which are major components of the plant immune response [55]. In maize, Pep1 plays an essential role in virulence by inhibiting plant peroxidases. The $\Delta p e p 1$ mutants induce strong plant defence responses, (e.g., papilla formation, $\mathrm{H}_{2} \mathrm{O}_{2}$ accumulation and host cell death) leading to an early block in pathogenic development of the fungus. Importantly, in vivo immunolocalization, live- 
cell imaging and plasmolysis assays clearly indicate that Pep1 is an apoplastic effector that accumulates at points of cell-to-cell passage [55,56]. At sites where mutant strains attempt

penetration, $\mathrm{H}_{2} \mathrm{O}_{2}$ strongly accumulates in the cell walls. Moreover, bimolecular fluorescence

complementation (BiFC) assays indicate interaction between Pep1 and the secreted maize defence peroxidase POX12 in planta. Pep1 seems to be crucial for scavenging plant ROS, facilitating the penetration of the fungus $[55,56]$. 


\section{Effector targeting microRNA biosynthesis pathway}

Highly-specialized small RNAs, so-called microRNA (miRNA), have recently been shown to regulate pattern-triggered immunity (PTI) during bacterial, oomycete and fungal invasion of plants $\left[57^{* *}, 58^{*}, 59^{*}\right]$. The PSR1 protein (Phythophthora Supressor of RNA Silencing 1) directly targets an essential Arabidopsis protein called PINP1 (PSR1-interacting Protein 1) required for accumulation of distinct classes of miRNA promoting disease development. Further study has shown that silencing the PINPI gene impairs the assembly of microRNA-processing complex in the nucleus, attenuating PTI and promoting infection [57**].

\section{Effectors that modulate host metabolism}

The corn smut disease, caused by U. maydis, is characterized by tumor formation and anthocyanin induction. Tanaka et al. [60**] have reported induction of anthocyanin biosynthesis by the $U$. maydis effector called Tin2. Tin2 is translocated to the maize cytoplasm where it binds to and stabilizes ZmTTK1 kinase, leading to activation of transcription factors involved in the anthocyanin biosynthesis pathway. These results suggest that Tin2 likely redirects metabolites into the anthocyanin pathway in order to decrease their availability for other defense responses.

The U. maydis cytoplasmic effector chorismate mutase (Cmu1) is highly expressed during biotrophic invasion and plays an important role in virulence [61]. This fungal enzyme catalyzes the conversion of plant chorismate to prephenate in the shikimate pathway leading a shift in host metabolism towards aromatic amino acid biosynthesis and away from biosynthesis 
of the defence hormone salicylic acid. Maize plants infected by $\Delta c m u 1$ mutants show increased levels of salicylic acid, providing significant resistance to the fungus [61].

\section{$3^{\text {rd }}$ Strategy: Remodeling the fungal cell walls}

A series of elegant models explain how different fungi evade exposition of elicitor-active cell wall polymers in planta including chitin deacetylation $\left[62,63,64,65^{* *}\right]$, shielding of the glucanchitin network by alpha-1,3-glucan [66**] and readjustment of the beta-1,3/1,6-glucan content of hyphal cell walls $\left[67^{*}\right]$.

\section{Chitin deacetylation}

As chitosan is not a good substrate for plant chitinases, fungal pathogens convert chitin to chitosan in the attempt to shield the fungal cell wall from release of chitin oligosaccharides that serve as PAMPs. Chitin deacetylase, the enzyme that catalyzes the conversion of chitin to chitosan by the deacetylation of $\mathrm{N}$-acetyl-D-glucosamine residues, was first identified and partially purified from extracts of the fungus Mucor rouxii [68]. Since then, the presence of this enzyme activity has been reported in several other fungi $[62,63,64]$. Through chitin and chitosan staining methods, El Guedari and colleagues [62] have found that chitosan, but not chitin, is present on the surface of the cell walls of biotrophic infection structures of the wheat stem rust fungus Puccinia graminis f. sp. tritici, the broad bean rust fungus Uromyces fabae, and the maize anthracnose fungus, Colletotrichum graminicola. Indeed, transcriptome analysis (RNA-seq) clearly indicated that at least four chitin deacetylases are overexpressed during biotrophic 
development of the cacao pathogen Moniliophthora perniciosa [65**]. In this context, chitin deacetylases may impair chitin-triggered immunity and promote $M$. perniciosa virulence. Furthermore, M. oryzae has been shown to mask surface exposed chitin during the first hours of biotrophic development (Figure 3). Interestingly, invasive hyphae in first-invaded rice cells showed only slight staining when labeled with fluorescently-labelled wheat germ agglutinin, which identifies chitin. However, these fluorescent signals became stronger in the secondinvaded cells, and decreased upon the chitinase treatment, indicating the recurrence of elicitoractive chitin in further colonized rice cells. [64*].

\section{Alpha-1,3-glucan apposition}

Alpha-1,3-glucan, a non-degradable polysaccharide in plants, represents a key feature in fungal cell walls formed in planta [63]. In M. oryzae, this polysaccharide is essential for evasion of hyphal PAMP-triggered immunity during the infection process [66**] (see Figure 3). Additionally, $\alpha-1,3$-glucan plays a protective role for this fungus against plant lytic enzymes, such as chitinases. In fact, $M$. oryzae mutants containing deletions of $\alpha$-1,3-glucan synthase (AGS1) lack hyphal $\alpha-1,3$-glucan and are non-pathogenic in rice. Importantly, this infectionspecific masking of the glucan-chitin network by $\alpha-1,3$-glucan is mechanistically conserved among M. oryzae, C. miyabeanus and Rhizoctonia solani. Diseases caused by these fungi are drastically reduced in transgenic rice plants expressing a bacterial $\alpha-1,3$-glucanase [66**]. The current availability of genome and transcriptomes sequences allowed identification of putative AGS1 orthologs in other biotrophic fungal pathogens, such as the rust fungus $P$. graminis, the corn anthracnose fungus $C$. graminicola and the blotch fungus $M$. graminicola, which suggests this might be a common strategy $\left[66^{* *}\right]$. 
Readjustment of hyphal wall beta-1,3/1,6-glucan content

Not only chitin, but also branched $\beta-1,3 / 1,6$-glucan fragments are known as highly potent elicitors of defence responses in plants [69] even though enzymatic modifications or sequestration of $\beta-1,3$-glucan fragments have not yet been reported. Additionally mechanisms leading to evasion of $\beta$-1,3-glucan-triggered immune responses have not been well understood for many filamentous pathogens. Oliveira-Garcia and Deising [67*] have performed key experiments on synthesis of $\beta$-1,3-glucan during the infection process of $C$. graminicola, using gene silencing and overexpression assays for targeting the $\beta$-1,3-glucan synthase (GLS1) gene. Glucan synthase is a single-copy gene in most filamentous fungi. Infection structure-specific expression of GLSI controls the exposition of $\beta$-glucan in C. graminicola, presumably to evade plant recognition. Indeed, high expression levels of GLS1 during biotrophic development trigger massive plant defence responses. This represents a novel strategy for establishing a biotrophic interaction and evasion of PAMP triggered immunity.

\section{Conclusions and outlook}

Fungal and oomycete crop pathogens remain major food security threats and studies on durable disease resistance must become a top priority. Increasing our knowledge of the pathogenic mechanisms adopted by filamentous eukaryotic pathogens is essential for designing durable methods for disease control. Exploring the biotrophic interfaces and deciphering precisely the composition of interfacial matrices, the biochemical function of effectors, and fungal cell wall dynamics to elucidate how pathogens successfully colonize and reproduce on their host plants is 
a challenge in the field of fungal and oomycete pathology. Even with the recent availability of genome-wide transcriptomes, we are still at the beginning of this challenging road to understand the cellular biology of the complex sets of biotrophic interfaces. One of the best routes to provide sustainable disease control involves incorporating $R$ genes into agricultural crops. In this context, the identification of new $A V R$ gene- $R$ gene pairs and the application of novel techniques targeting pathogen effector genes and genes involved with synthesis of the biotrophic interface components, may represent future relevant strategies for control of several important crop diseases.

\section{Acknowledgements}

Our research was supported by Agriculture and Food Research Initiative Competitive Grant number 2012-67013-19291 from the USDA National Institute of Food and Agriculture. This is contribution number 15-341-J from the Kansas Agricultural Experiment Station. 


\section{Recommended reading}

* of special interest

** of outstanding interest

$\left[3^{*}\right]$

This comprehensive review dissects important plant PAMP/PRR pairs and illustrates key molecular strategies employed by plant PRRs to activate innate immune responses.

$[9 * *]$

This paper supports the concept that the EHM is differentiated in protein content from the plant plasma membrane (PM). The authors demonstrated though live-cell imaging assays that plasmosdesmata-localized protein 1 (PDLP1) is an EHM-associated protein and regulates callose deposition during downy mildew infection.

$\left[14^{*}\right]$

This review highlights the pathogen-specific modulation of sugar transporter mRNAs in planta in order to promote pathogen nutrition and suppress plant immunity during plant infection.

$[22 * *]$

This interesting global genome and transcriptome analysis identifies novel isolate-specific effectors and pathogenesis-related genes of M. oryzae.

$[31 * *]$

Remarkable demonstration that long-distance early endosome trafficking is required for effector production during plant infection by the corn pathogen Ustilago maydis.

$[32 * *]$

A recent breakthrough on secretion of fungal effectors: The distinct secretion pathways of cytoplasmic and apoplastic effectors of the rice blast pathogen, M. oryzae. Apoplastic effectors are delivered to the EIHMx by the conventional Golgi-dependent secretion system. Cytoplasmic effectors are secreted by a golgi-independent pathway involving exocyst and SNARE proteins.

$\left[33^{*}\right]$

Comprehensive review focusing on plant cell wall-degrading enzymes and their secretion in plant-pathogenic fungi. These authors illustrate the distinct case study of protein secretion in Magnaporthe oryzae during host plant invasion.

$[35 * *]$

This study reports use of an effectoromics pipeline in tobacco to characterize subcellular localization and plant interactors for candidate effectors of the poplar rust fungus Melampsora larici-populina. This is the first report that effectors from a filamentous eukaryotic plant pathogen localize to host chloroplasts and mitochondria. 
$[47]^{* *}$

This study identified and characterized the novel $U$. maydis effector SGT1, which is essential for tumor development in leaf cells and modulation of plant immune responses.

[54*]

This paper reports the importance of the $N$-glycosylation of Slp1 for in planta functionality of this LysM effector.

$\left[57^{* *}\right]$

This remarkable study describes a new Phytophthora effector that blocks the production of specific classes plant microRNA, which is essential to regulate the pattern-triggered immunity (PTI) during oomycete and fungal invasion in plants. See also $\left[58^{*}, 59^{*}\right]$.

\section{$[60 * *]$}

This study indentified a novel effector, Tin2, which targets maize anthocyanin biosynthesis and promotes virulence in $U$. maydis.

\section{$[65 * *]$}

This elegant transcriptome analysis reported many chitin deacetylases and candidates effectors required for the biotrophic interaction Theobroma cacao - Moniliophthora perniciosa. This basidiomycete is significant threat to cacao production in Brazil.

$\left[66^{* *}\right]$

This remarkable study demonstrated that $\alpha$-1,3-glucan masks the cell walls of $M$. oryzae during biotrophic invasion in order to evade PAMP-triggered immunity.

$\left[67^{*}\right]$

This paper reports the infection structure-specific expression of glucan synthase gene controlling the exposition of elicitor active $\beta$-glucan during biotrophic invasion of $C$. graminicola. 


\section{Figures legends}

\section{Figure 1.}

Powdery mildew haustoria and rice blast invasive hyphae illustrate unique biotrophic interfaces inside plant cells. (a) Powdery mildew fungi such as the barley pathogen, Blumeria graminis f.sp. hordei, are obligate biotrophs. Once a conidium germinates, it forms a non-melanized appressorium that is attached to the leaf surface by adhesive compounds secreted by the fungus. The barley plant responds to the pathogen even before appressorium penetration by forming a papilla (brown structure), which is a cell wall apposition that contains callose (linear $\beta-1,3-$ glucan), phenolic compounds, lignin, reactive oxygen species, proteins and even membranes and exosomes; it is thought to function as a physical barrier to penetration. If penetration is successful, the fungus forms a haustorium, which is a specialized, terminal feeding structure that invaginates the host plasma membrane. This so-called extrahaustorial membrane (EHM) is highly specialized with a unique composition. The interface between the haustorial cell wall (FCW) and the EHM is called the extrahaustorial matrix (EHMx), which is sealed off by a neckband structure (NB; dark green structure). Powdery mildews deliver effectors, other compounds, and even vesicles, exosomes delivered from multivesicular bodies (MVBs), into the EHMx [12]. Plant MVBs also appear to deliver components into the EHMx. FHC, fungal haustorial cytosol; FPM, fungal plasma membrane; PC, plant cytosol.

(b) The blast fungus Magnaporthe oryzae is a hemibiotroph. Once a conidium germinates, it forms a robust, heavily-melanized appressorium that generates turgor pressure of $8 \mathrm{MPa}$ to power penetration. If penetration is successful, the fungus forms a filamentous primary invasive hypha that invaginates the host plasma membrane and establishes invasion of living host cells. Bulbous invasive hyphae (IH) emerge from the primary hyphae to continue biotrophic growth. These biotrophic hyphae secrete many specialized effectors. Cytoplasmic effectors massively accumulate in the biotrophic interfacial complex (BIC) (gradient yellow-red structure) and are translocated to the rice cytoplasm and/or nuclei (red structures). Apoplastic effectors accumulate in the interface (green) between the fungal cell wall and plant membrane that tightly surrounds $\mathrm{IH}$, called the extrainvasive hyphal membrane (EIHM). The EIHMx appears sealed into a separate compartment by a neckband-like structure (NB; dark green structure). Dynamic cytoplasmic strands are observed connecting the rice cytoplasm around the BIC and the cytoplasm beneath the appressorium (red lines). After filling the first-invaded cell, the fungus penetrates through the rice cell wall into neighboring cells, and continues its biotrophic life style, as indicated by formation of $\mathrm{IH}$ with new BICs. Host cells appear dead once the fungus has invaded neighboring cells, and effector fluorescence in BICs is reduced, as indicated here by reduced intensity of green color in the EHMx and red color in the BIC and nucleus in the firstinvaded cell. PPM, plant plasma membrane; EHMx, extrahaustorial matrix; FCW, fungal cell wall. 


\section{Figure 2.}

Strategic secretion and localization of $M$. oryzae effectors in planta. (a) This scheme shows the two distinct secretion systems of $M$. oryzae effectors. The Cartoon represents a bulbous invasive hypha (IH) at 24-28 h.p.i. (hours post-inoculation) inside a rice cell. The EIHM (dark green dashed line) continues around the BIC. Apoplastic effectors (dark green circles), including Slp1 (LysM effector) and Bas4 (Biotrophy-associated secreted protein 4, unknown function), accumulate in the EIHM compartment surrounding the IH cell wall, outlining the IH. Secretion of these effectors is sensitive to treatment with Brefeldin A (BFA), which blocks conventional Golgi-dependent secretion in fungi. In contrast, cytoplasmic effectors (red circles), including AVR effectors AvrPiz-t, AvrPita, and Pwl2 accumulate in BICs, here shown beside the firstdifferentiated bulbous IH cell. Furthermore, cytoplasmic effectors also accumulate inside the EIHM surrounding the BIC-associated cells (the primary hypha and first-differentiated bulbous IH cell), but they do not outline subsequently formed bulbous IH cells. The cytoplasmic effectors are secreted by a nonconventional, BFA-insensitive secretion pathway involving the exocyst and SNARE protein Sso1. Remarkably, cytoplasmic effectors move from cell-to-cell in the plant, apparently through plasmodesmata. N, fungal nucleus; ER, endoplasmic reticulum; G, Golgi apparatus; V, transport vesicle. (Modified after [32**]).

(b) Live-cell imaging of an $M$. oryzae strain expressing AvrPiz-t:mCherry:NLS and Bas4:GFP at 30 h.p.i. inside a rice cell. AvrPiz-t targets the rice ubiquitination system and suppresses plant defence responses. The NLS (nuclear localization signal) helps to visualize fluorescently-labeled proteins that are translocated to the host cytoplasm by concentrating them into the rice nucleus. "merge" shows the partial co-localization (yellow fluorescence) of AvrPiz-t (red fluorescence) and Bas4 (green fluorescence) in the BIC (arrow). Arrowheads indicate the rice nucleus. "AvrPiz-t:mCherry:NLS" shows the red fluorescence channel alone indicating translocation of AvrPiz-t and localization in the rice nucleus (arrowhead). "Bas4:GFP" shows the green fluorescence channel alone indicating absence of Bas4 in the rice nucleus (Arrowhead). Bar $=5$ $\mu \mathrm{m}$. (Courtesy: Chang Hyun Khang, Kansas State University, USA; From: [46]). 
Figure 3.

Strategic remodeling of the $M$. oryzae cell walls help the fungus evade recognition. The rice plasma membrane carries conserved pattern recognition receptors (PRR) (e.g., ERR, Ergosterol receptor; CERiP, Chitin receptor; GLR, glucan receptor) restricting the spectra of pathogenic microorganisms. The EIHMx contains apoplastic effectors, such as the chitin-binding effector Slp1. Rice plants secrete lytic enzymes into the apoplast, such as the chitinase PR3, which releases chitin oligomers from the fungal cell wall. Slp1 recognizes and sequesters these chitin oligomers, evading recognition by host chitin receptors. Deacetylation of chitin (chitosan yellow hexagons) and $\alpha-1,3$-glucan apposition protects the fungal cell wall against plant lytic enzymes that release PAMPs. M. oryzae biotrophy-specific sugar transporters probably function in sugar uptake for hyphal nutrition. PPM, plant plasma membrane; EIHM, extrainvasive hyphal membrane; EIHMx, extrainvasive hyphal matrix; PR3, pathogenesis-related protein 3 (plant chitinase); Slp1, Chitin binding-like effector; FPM, fungal plasma membrane. ST, sugar transporters. 


\section{References}

1. Fisher M C, Henk DA, Briggs CJ, Brownstein JS, M adoff LC, M CCraw SL, Gurr SJ : Emerging fungal threats to animal, plant and ecosystem health. Nature 2012, 485:186-194.

2. Xu W, Meng Y, Surana P, Fuerst G, Nettleton D, Wise RP: The knottin-like Blufensin family regulates genes involved in nuclear import and the secretory pathway in barley-powdery mildew interactions. Front Plant Sci 2015, 6:409.

3. Zipfel C: Plant pattern-recognition receptors. Trends Immunol 2014, 35:345-351.

4. Cui $\mathrm{H}$, Tsuda K, Parker JE: Effector-triggered immunity: from pathogen perception to robust defense. Annu Rev Plant Biol 2015, 66:6.1-6.25.

5. Sanabria N, Goring D, Nürnberger T, Dubery I: Self/nonself perception and recognition mechanisms in plants: a comparison of self-incompatibility and innate immunity. New Phytologist 2008, 178:503-514.

6. DeYoung BJ, Innes RW: Plant NBS-LRR proteins in pathogen sensing and host defense. Nat immunol 2006, 7:1243-1249.

7. Petre B, Joly DL, Duplessis S: Effector proteins of rust fungi. Front Plant Sci 2014, 5.

8. Kankanala P, Czymmek K, Valent B: Roles for rice membrane dynamics and plasmodesmata during biotrophic invasion by the blast fungus. Plant Cell 2007, 19:706-724.

9. Caillaud M-C, Wirthmueller L, Sklenar J, Findlay K, Piquerez SJM, Jones AME, Robatzek S, Jones JDG, Faulkner C: The plasmodesmal protein PDLP1 localises to haustoria-associated membranes during downy mildew infection and regulates callose deposition. Plos Pathog 2014, 10:e1004496.

10. Bozkurt TO, Belhaj K, Dagdas YF, Chaparro-Garcia A, Wu C-H, Cano LM, Kamoun S: Rerouting of Plant Late Endocytic Trafficking Toward a Pathogen Interface. Traffic 2015, 16:204-226.

11. Perfect SE, Green JR: Infection structures of biotrophic and hemibiotrophic fungal plant pathogens. Mol Plant Pathol 2001, 2:1464-6722.

12. Micali CO, Neumann U, Grunewald D, Panstruga R, O'Connell R: Biogenesis of a specialized plantfungal interface during host cell internalization of Golovinomyces orontii haustoria. Cell. M icrobiol. 2011, 13:210-226.

13. Green JR, Carver TLW, Gurr SJ: The formation and function of infection feeding structures. In In powdery mildews: a comprehensive treatise. Edited by Belanger R, Bushnell W, Dik A, Carver T: APS; 2002:62-82.

14. Eom J-S, Chen L-Q, Sosso D, Julius BT, IW L, Qu X-Q, Braun DM , Frommer WB: SWEETs, transporters for intracellular and intercellular sugar translocation. Curr Opin Plant Biol 2015, 25:53-62.

15. Voegele RT, Mendgen KW: Nutrient uptake in rust fungi: how sweet is parasitic life. Euphytica 2011, 179:41-55.

16. Lingner $U$, Muench $S$, Deising $H B$, Sauer $N$ : Hexose transporters of a hemibiotrophic plant pathogen: functional variations and regulatory differences at different stages of infection. J Biol Chem 2011, 286:20913-20922.

17. Herbers K, Meuwly P, Metraux J-P, Sonnewald U: Salicylic acid-independent induction of pathogenesis-related protein transcripts by sugars is dependent on leaf developmental stage. FEBS Letters 1996, 397:239-244.

18. Wahl R, Wippel K, Goos S, Kaemper J, Sauer N: A novel high-affinity sucrose transporter is required for virulence of the plant pathogen Ustilago maydis. Plos Biol 2010, 8:e1000303. 
19. Talbot $\mathrm{NJ}$ : Living the sweet life: how does a plant pathogenic fungus acquire sugar from plants? Plos Biol 2010, 8:e1000308.

20. Bolton MD, Van Esse HP, Vossen JH, De Jonge R, Stergiopoulos I, Stulemeijer IJE, Van Den Berg GCM, Borrás-Hidalgo O, Dekker HL, De Koster CG, et al.: The novel Cladosporium fulvum Iysin motif effector Ecp6 is a virulence factor with orthologues in other fungal species. Mol Microbiol 2008, 69:119-136.

21. Thakur K, Chawla V, Bhatti S, Swarnkar MK, Kaur J, Shankar R, Jha G: De novo transcriptome sequencing and analysis for Venturia inaequalis, the devastating apple scab pathogen. PLOS One 2013, 8:e53937.

22. Dong Y, Li Y, Zhao M, Jing M, Liu X, Liu M, Guo X, Zhang X, Chen Y, Liu Y, et al.: Global genome and transcriptome analyses of Magnaporthe oryzae epidemic isolate 98-06 uncover novel effectors and pathogenicity-related genes, revealing gene gain and lose dynamics in genome evolution. Plos Pathog 2015, 11:e1004801.

23. O'Connell RJ, Thon MR, Hacquard S, Amyotte SG, Kleemann J, Torres MF, Damm U, Buiate EA, Epstein L, Alkan N, et al.: Lifestyle transitions in plant pathogenic Colletotrichum fungi deciphered by genome and transcriptome analyses. Nature 2012, 44:1060-1065.

24. Mendgen K, Hahn M : Plant infection and the establishment of fungal biotrophy. Trends Plant Sci 2002, 7:352-356.

25. Mueller O, Kahmann R, Aguilar G, Trejo-Aguilar B, Wub A, De Vries RP: The secretome of the maize pathogen Ustilago maydis. Fungal Genet Biol 2008, 45.

26. Garnica DP, Nemri A, Upadhyaya NM, Rathjen JP, Dodds PN: The ins and outs of rust haustoria. Plos Pathog 2014, 10:e1004329

27. Kleemann J, Rincon-Rivera LJ, Takahara H, Neumann U, Ver E, Van Themaat L, Van der Does HC, Hacquard S, Stueber K, Will I, et al.: Sequential delivery of host-induced virulence effectors by appressoria and intracellular hyphae of the phytopathogen Colletotrichum higginsianum. Plos Pathog 2012, 8:e1002643.

28. Doehlemann G, Wahl R, Horst RJ, Voll LM, Usadel B: Reprogramming a maize plant: transcriptional and metabolic changes induced by the fungal biotroph Ustilago maydis. Plant J 2008, 56:181195.

29. Rafiqi M, Ellis JG, Ludowici VA, Hardham AR, Dodds PN: Challenges and progress towards understanding the role of effectors in plant-fungal interactions. Curr Opin Plant Biol 2012, 15:477-482.

30. Yoshida K, Saitoh H, Fujisawa S, Kanzaki H, M atsumura H, Yoshida K, Tosa Y, Chuma I, Takano Y, Win $\mathrm{J}$, et al.: Association genetics reveals three novel avirulence genes from the rice blast fungal pathogen Magnaporthe oryzae. Plant Cell 2009, 21: 1573-1591

31. Bielska E, Higuchi Y, Schuster M, Steinberg N, Kilaru S, Talbot NJ, Steinberg G: Long-distance endosome trafficking drives fungal effector production during plant infection. Nature Communications 2014, 5:5097.

32. Giraldo M C, Dagdas YF, Gupta YK, M entlak TA, Yi M, Martinez-Rocha AL, Saitoh H, Terauchi R, Talbot $\mathrm{NJ}$, Valent $\mathrm{B}$ : Two distinct secretion systems facilitate tissue invasion by the rice blast fungus Magnaporthe oryzae. Nature Communications 2013, 4:1996.

33. Kubicek CP, Starr TL, Glass NL: Plant cell wall-degrading enzymes and their secretion in plantpathogenic fungi. Ann Rev Phytopathol 2014., 52:427-451.

34. Khang $\mathrm{CH}$, Berruyer R, Giraldo MC, Kankanala P, Park S-Y, Czymmek K, Kang S, Valent B: Translocation of Magnaporthe oryzae effectors into rice cells and their subsequent Cell-to-Cell movement. Plant Cell 2010, 22:1388-1403. 
35. Petre B, Saunders DGO, Sklenar J, Lorrain C, Win J, Duplessis S, Kamoun S: Candidate effector proteins of the rust pathogen Melampsora larici-populina target diverse plant cell compartments M ol Plant Microbe In 2015.

36. Oliva RF, Cano LM, Raffaele S, Win J, Bozkurt TO, Belhaj K, Oh S-K, Thines M, Kamoun S: A recent expansion of the RXLR effector gene Avrblb2 is maintained in global populations of Phytophthora infestans indicating different contributions to virulence. Mol Plant Microbe In 2015.

37. Giraldo MC, Valent B: Filamentous plant pathogen effectors in action. Nature 2013, 11:800-814.

38. Delaunois $B$, Jeandet $P$, Clément $C$, Baillieul $F$, Dorey $S$, Cordelier S: Uncovering plant-pathogen crosstalk through apoplastic proteomic studies. Front Plant Sci 2014, 5:249.

39. Rose JKC, Ham K-S, Darvill AG, Albersheim P: Molecular cloning and characterization of glucanase inhibitor proteins: coevolution of a counterdefense mechanism by plant pathogens. Plant Cell 2002, 14:1329-1345.

40. Mueller AN, Ziemann S, Treitschke S, Aßmann D, Doehlemann G: Compatibility in the Ustilago maydis Maize Interaction Requires Inhibition of Host Cysteine Proteases by the Fungal Effector Pit2. PLoS Pathog 2013, 9:e1003177.

41. Rooney HCE, Van Klooste JW, Van der Hoorn RAL, Joosten MHAJ, Jones JDG, De Wit PJGM: Cladosporium Avr2 inhibits tomato Rcr3 protease required for Cf- 2-dependent disease resistance. Science 2005, 308:1783-1786.

42. Song J, Win J, Tian M, Schornack S, Kaschani F, llyas M, Van der Hoorn RAL, Kamoun S: Apoplastic effectors secreted by two unrelated eukaryotic plant pathogens target the tomato defense protease Rcr3. Proc Natl Acad Sci USA 2009, 106:1654-1659.

43. Kemen $E$, Kemen $A$, Ehlers $A$, Voegele $R, M$ endgen $K$ : A novel structural effector from rust fungi is capable of fibril formation. Plant J 2013, 75:767-780.

44. Bos JIB, Armstrong M R, Gilroy EM, Boevink PC, Hein I, Taylor RM , Zhendong T, Engelhardt S, Vetukuri RR, Harrower B, et al.: Phytophthora infestans effector AVR3a is essential for virulence and manipulates plant immunity by stabilizing host E3 ligase CMPG1. PNAS 2010, 107:9909-9914.

45. Trujillo M, Shirasu K: Ubiquitination in plant immunity. Curr Opin Plant Biol 2010, 13:402-408.

46. Park C-H, Chen S, Shirsekar G, Zhou B, Khang CH, Songkumarn P, Afzal AJ, Ning Y, Wang R, Bellizzi M, et al.: The Magnaporthe oryzae effector AvrPiz-t targets the RING E3 ubiquitin ligase APIP6 to suppress pathogen-associated molecular pattern-triggered immunity in rice. Plant Cell 2012, 24:4748-4762.

47. Redkar A, Hoser R, Schilling L, Zechmann B, Krzymowska M, Walbot V, Doehlemann G: A secreted effector protein of Ustilago maydis guides maize leaf cells to form tumors. Plant Cell 2015, 27:1332-1351.

48. Felix G, Regenass M, Boller T: Specific perception of subnanomolar concentrations of chitin fragments by tomato cells: induction of extracellular alkalinization, changes in protein phosphorylation, and establishment of a refractory state. The Plant Journal 1993, 4:307-316.

49. Shimizu T, Nakano T, Takamizawa D, Desaki Y, Ishii-M inami N, Nishizawa Y, Minami E, Okada K, Yamane $\mathrm{H}$, Kaku $\mathrm{H}$, et al.: Two LysM receptor molecules, CEBiP and OsCERK1, cooperatively regulate chitin elicitor signaling in rice. Plant J 2010, 64:204-214.

50. Kombrink A, Thomma BPHJ: LysM effectors: secreted proteins supporting fungal life. Plos Pathog 2013, 9:e1003769.

51. De Jonge R, Van Esse HP, Kombrink A, Shinya T, Desaki Y, Bours R, Van der Krol S, Shibuya N, Joosten M HAJ, Thomma BPHJ: Conserved fungal LysM effector Ecp6 prevents chitin-triggered immunity in plants. Science 2010, 329:953-955.

52. Marshall R, Kombrink A, M otteram J, Loza-Reyes E, Lucas J, Hammond-Kosack KE, Thomma BPHJ, Rudd JJ: Analysis of two in planta expressed LysM effector homologs from the fungus 
Mycosphaerella graminicola reveals novel functional properties and varying contributions to virulence on wheat. Plant Physiol 2011, 156:756-769.

53. Mentlak TA, Kombrink A, Shinya T, Ryder LS, Otomo I, Saitoh H, Terauchi R, Nishizawa Y, Shibuya N, Thomma BPHJ, et al.: Effector-mediated suppression of chitin-triggered immunity by Magnaporthe oryzae is necessary for rice blast disease. Plant Cell 2012, 24:322-335.

54. Chen X-L, Shi T, Yang J, Shi W, Gao X, Chen D, Xu X, Xu J-R, Talbot NJ, Peng Y-L: N-glycosylation of effector proteins by an $\alpha-1,3-$ mannosyltransferase is required for the rice blast fungus to evade host innate immunity. Plant Cell 2014, 26:1360-1376.

55. Hemetsberger C, Mueller AN, Matei A, Herrberger C, Hensel G, Kumlehn J, Mishra B, Sharma R, Thines $M$, Hueckelhoven $R$, et al.: The fungal core effector Pep1 is conserved across smuts of dicots and monocots. New Phytologist 2015.

56. Doehlemann G, Van der Linde K, Aßmann D, Schwammbach D, Hof A, Mohanty A, Jackson D, Kahmann R: Pep1, a secreted effector protein of Ustilago maydis, is required for successful invasion of plant cells. Plos Pathog 2009, 5:e1000290.

57. Qiao Y, Shia J, Zhaia Y, Houa Y, Ma W: Phytophthora effector targets a novel component of small RNA pathway in plants to promote infection. PNAS 2015, 112:5850-5855.

58. Wong J, Gao L, Yang Y, Zhai J, Arikit S, Yu Y, Duan S, Chan V, Xiong Q, Yan J, et al.: Roles of small RNAs in soybean defense against Phytophthora sojae infection. Plant J 2014, 79:928-940.

59. Bologna NG, Voinnet 0 : The diversity, biogenesis, and activities of endogenous silencing small RNAs in Arabidopsis. Annu Rev Plant Biol 2014, 65:473-503.

60. Tanaka S, Brefort T, Neidig N, Djamei A, Kahnt J, Vermerris W, Koenig S, Feussner K, Feussner I, Kahmann R: A secreted Ustilago maydis effector promotes virulence by targeting anthocyanin biosynthesis in maize. eLIFE 2015, 3:e01355.

61. Djamei A, Schipper K, Rabe F, Ghosh A, Vincon V, Kahnt J, Osorio S, Tohge T, Fernie AR, Feussner I, et al.: Metabolic priming by a secreted fungal effector. Nature 2011, 478:395-398.

62. El Gueddari NE, Rauchhaus U, Moerschbacher BM, Deising HB: Developmentally regulated conversion of surface-exposed chitin to chitosan in cell walls of plant pathogenic fungi. New Phytologist 2002, 156:103-112.

63. Fujikawa T, Kuga Y, Yano S, Yoshimi A, Tachiki T, Abe K, Nishimura M: Dynamics of cell wall components of Magnaporthe grisea during infectious structure development. Mol Microbiol 2009, 73:553-570.

64. Mochizuki S, Saitoh K-i, Minami E, Nishizawa Y: Localization of probe-accessible chitin and characterization of genes encoding chitin-binding domains during rice-Magnaporthe oryzae interactions. J. Gen. Plant. Pathol. 2011, 77:163-173.

65. Teixeira PJPL, Thomazella DPdT, Reis O, do Prado PFV, do Rio MCS, Fiorin GL, José J, Costa GGL, Negri VA, Mondego JMC, et al.: High-resolution transcript profiling of the atypical biotrophic interaction between Theobroma cacao and the fungal pathogen Moniliophthora perniciosa. Plant Cell 2014, 26:4245-4269.

66. Fujikawa T, Sakaguchi A, Nishizawa Y, Kouzai Y, M inami E, Yano S, Koga H, M eshi T, Nishimura M: Surface $\alpha-1,3-$ Glucan facilitates fungal stealth infection by interfering with innate immunity in plants. Plos Pathog 2012, 8:e1002882.

67. Oliveira-Garcia E, Deising HB: Infection structure-specific expression of $\boldsymbol{\beta}$-1,3-glucan synthase is essential for pathogenicity of Colletotrichum graminicola and evasion of $\beta$-glucan-triggered immunity in maize. Plant Cell 2013, 25:2356-2378.

68. Araki Y, Ito E: A pathway of chitosan formation in Mucor rouxii. Enzymatic deacetylation of chitin. Eur J Biochem 1975, 55:71-78. 
69. Shetty NP, Jensen JD, Knudsen A, Finnie C, Geshi N, Blennow A, Collinge DB, Joergensen HJL: Effects of beta-1,3-glucan from Septoria tritici on structural defence responses in wheat. J Exp Bot $2009,60: 4287-4300$. 
Table 1.

A selection of well-characterized filamentous plant pathogen effectors targeting suppression of plant defences or evasion of host recognition

\begin{tabular}{|c|c|c|c|c|}
\hline Effector & Pathogen species & function & $\begin{array}{l}\text { In planta } \\
\text { localization }\end{array}$ & Reference \\
\hline GLI1 & $\begin{array}{l}\begin{array}{l}\text { Phytophthora } \\
\text { oxyporum, } \\
\text { nodorum } \\
\text { carbonum }\end{array} \text { and } \begin{array}{r}\text { Phasarium } \\
\text { Cochliobolus }\end{array} \\
\end{array}$ & glucanase inhibitor & apoplastic & {$[39]$} \\
\hline Pit2 & Ustilago maydis & cysteine protease inhibitor & apoplastic & {$[40]$} \\
\hline Avr2 & Cladosporium fulvum & $\begin{array}{l}\text { protease inhibitor; AVR effector for tomato } \mathrm{R} \\
\text { gene } C f-2\end{array}$ & apoplastic & {$[41,50]$} \\
\hline EPIC1 & Phytophthora infestans & protease inhibitor & apoplastic & [42] \\
\hline EPIC2B & P. infestans & protease inhibitor & apoplastic & [42] \\
\hline RTP1 & $\begin{array}{l}\text { Uromyces fabae, Uromyces } \\
\text { striatus and many other rust } \\
\text { species }\end{array}$ & $\begin{array}{l}\text { cysteine protease inhibitor; possible structural } \\
\text { function for stabilization of biotrophic infection } \\
\text { structures }\end{array}$ & $\begin{array}{l}\text { cytoplasmic/ } \\
\text { apoplastic }\end{array}$ & {$[26,7,43]$} \\
\hline Avr3a & P. infestans & $\begin{array}{l}\text { targets host ubiquitination; AVR effector for } \\
\text { potato protein gene } R 3 a\end{array}$ & cytoplasmic & [44] \\
\hline AvrPiz-t & Magnaporthe oryzae & $\begin{array}{l}\text { targets host ubiquitination; AVR effector for rice } \\
\text { R gene Piz- } t\end{array}$ & cytoplasmic & [46] \\
\hline Slp1 & M. oryzae & chitin oligomers sequestration & apoplastic & {$[53]$} \\
\hline Ecp6 & C. fulvum & chitin oligomers sequestration & apoplastic & {$[51]$} \\
\hline Avr4 & C. fulvum & $\begin{array}{l}\text { protects the fungal cell wall from degradation by } \\
\text { plant chitinases; AVR effector for tomato R gene } \\
C f-4\end{array}$ & apoplastic & {$[51]$} \\
\hline Mg1LysM & Mycosphaerella graminicola & $\begin{array}{l}\text { protects the fungal cell wall from degradation by } \\
\text { plant chitinases }\end{array}$ & apoplastic & {$[52]$} \\
\hline Mg3LysM & M. graminicola & $\begin{array}{l}\text { protect the fungal cell wall from degradation by } \\
\text { plant chitinases; blocks the elicitation of chitin- } \\
\text { induced plant defences }\end{array}$ & apoplastic & {$[52]$} \\
\hline Pep1 & U. maydis & peroxidase inhibitor & apoplastic & {$[56]$} \\
\hline Cmul & U. maydis & targets defence signaling & cytoplasmic & {$[61]$} \\
\hline PSR1 & Phytophthora sp. & targets plant microRNA biosynthesis pathway & cytoplasmic & {$[57]$} \\
\hline Tin2 & U. maydis & targets plant anthocyanin biosynthesis & cytoplasmic & {$[60]$} \\
\hline See 1 & U. maydis & $\begin{array}{l}\text { targets SGT1 (Suppressor of G2 allele of skp1) } \\
\text { and it is crucial for tumor progression in leaf } \\
\text { cells. }\end{array}$ & cytoplasmic & {$[47]$} \\
\hline Iug6 & M. oryzae & targets both salicylic acid and ethylene pathways & $\begin{array}{l}\text { putative } \\
\text { cytoplasmic }\end{array}$ & {$[22]$} \\
\hline
\end{tabular}




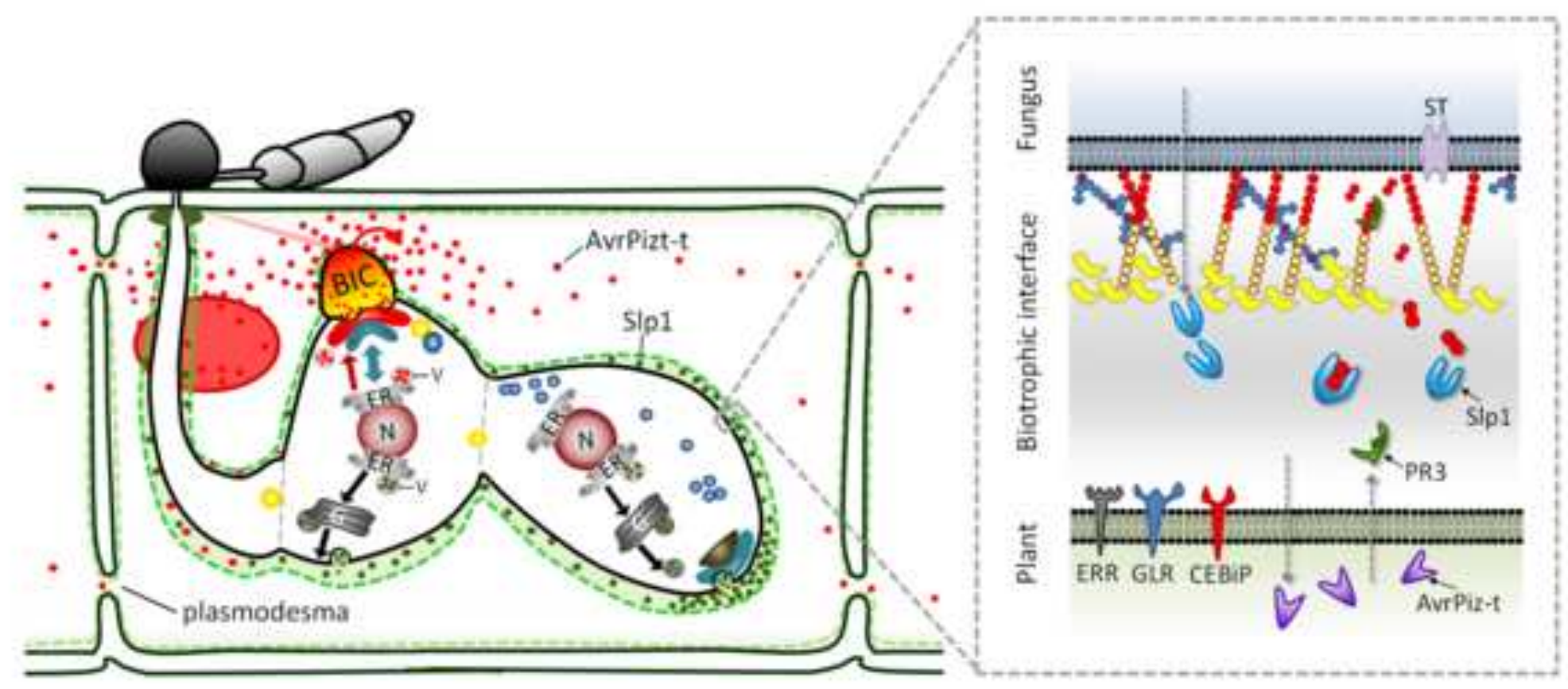



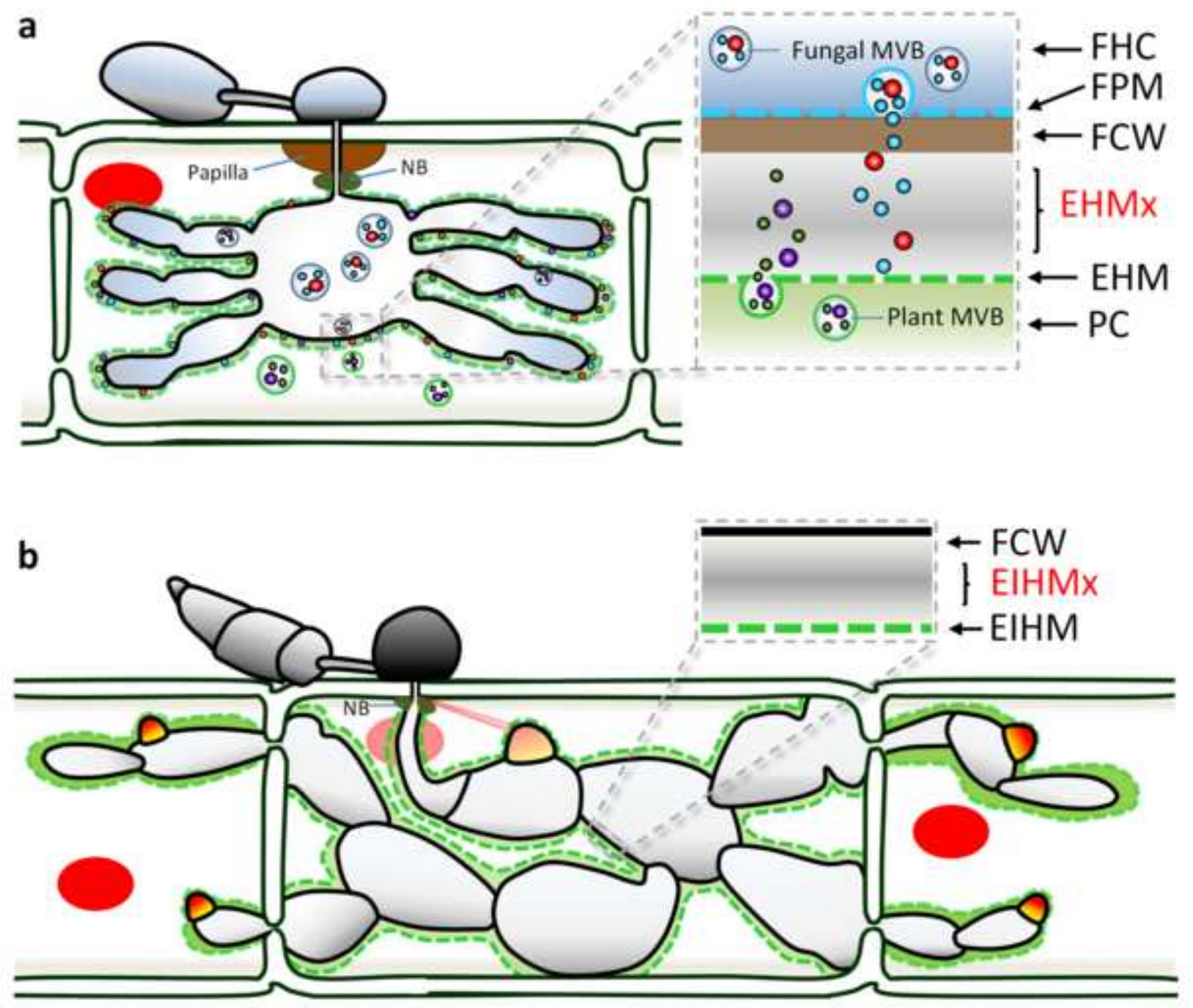
a

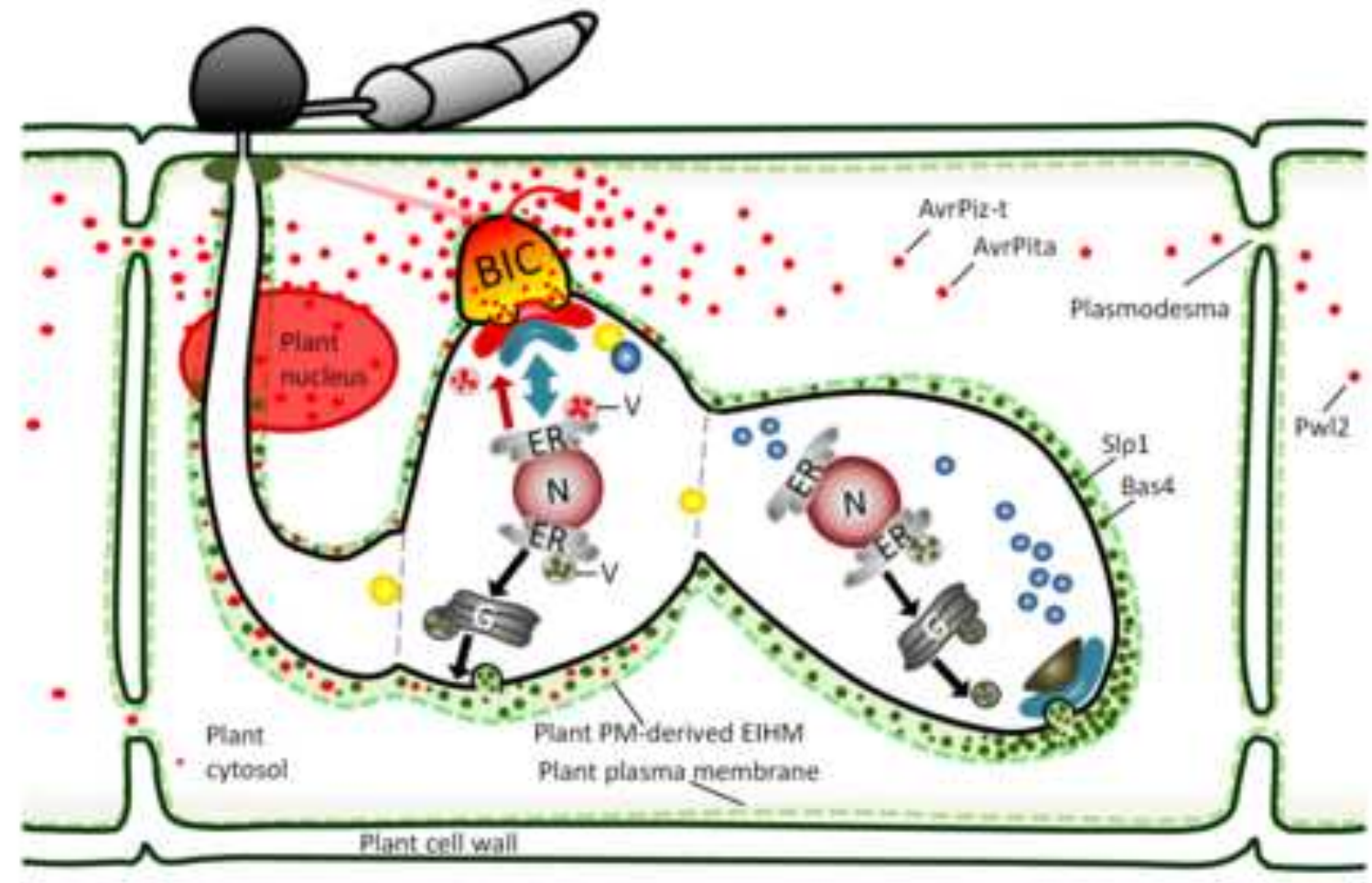

Fungal effector proteins Spitzenkörper markers

- Apoplastic

- Cytoplastic Mic1 Osnc1

Polarisome marker C Spa2
Exocyst complex markers Exo70 * Sec5 t-SNARE marker b

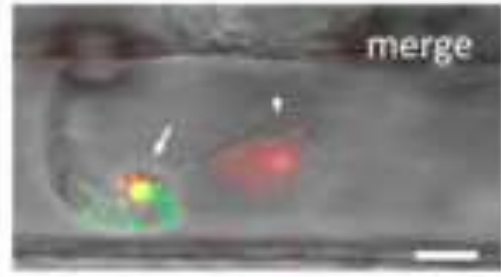

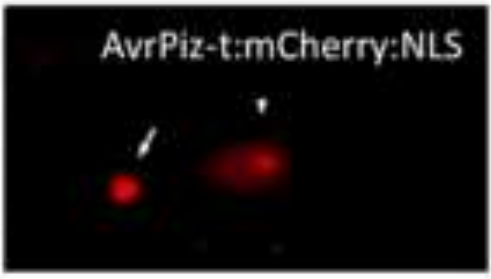

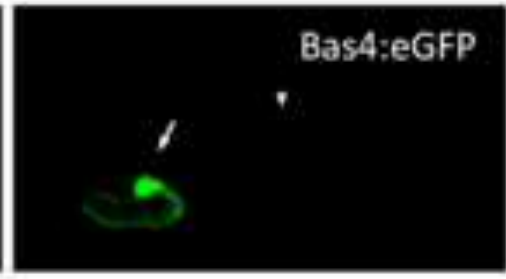




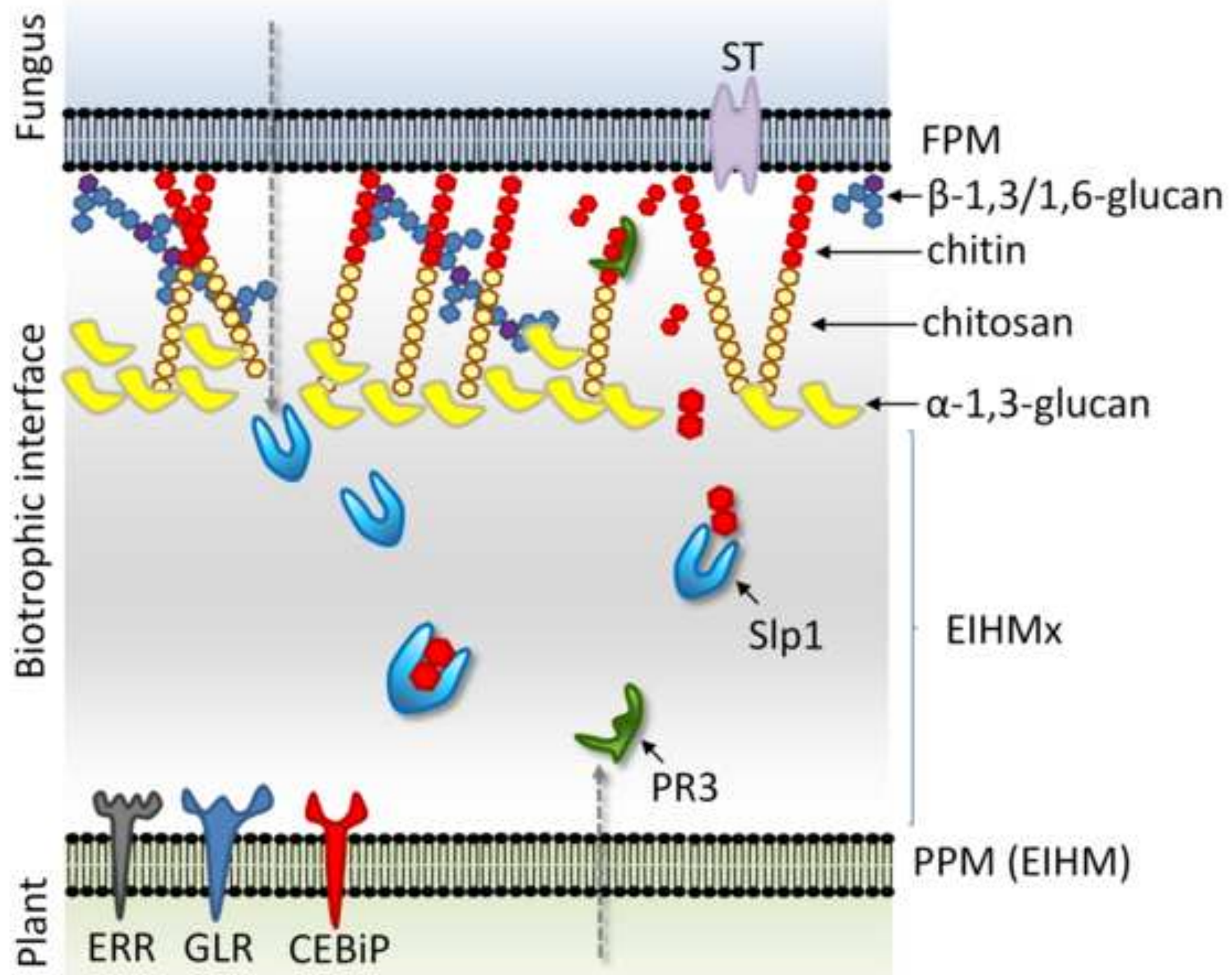


Table 1.

A selection of well-characterized filamentous plant pathogen effectors targeting suppression of plant defences or evasion of host recognition

\begin{tabular}{|c|c|c|c|c|}
\hline Effector & Pathogen species & function & $\begin{array}{l}\text { In planta } \\
\text { localization }\end{array}$ & Reference \\
\hline GLI1 & $\begin{array}{l}\begin{array}{l}\text { Phytophthora sojae, } \\
\text { oxyporum, } \\
\text { nodorum } \\
\text { carbonum }\end{array} \text { and } \begin{array}{r}\text { Phaeosphaeria } \\
\text { Cochliobolus }\end{array} \\
\end{array}$ & glucanase inhibitor & apoplastic & [39] \\
\hline Pit2 & Ustilago maydis & cysteine protease inhibitor & apoplastic & [40] \\
\hline Avr2 & Cladosporium fulvum & $\begin{array}{l}\text { protease inhibitor; AVR effector for tomato } \mathrm{R} \\
\text { gene } C f-2\end{array}$ & apoplastic & {$[41,50]$} \\
\hline EPIC1 & Phytophthora infestans & protease inhibitor & apoplastic & {$[42]$} \\
\hline EPIC2B & P. infestans & protease inhibitor & apoplastic & {$[42]$} \\
\hline RTP1 & $\begin{array}{l}\text { Uromyces fabae, Uromyces } \\
\text { striatus and many other rust } \\
\text { species }\end{array}$ & $\begin{array}{l}\text { cysteine protease inhibitor; possible structural } \\
\text { function for stabilization of biotrophic infection } \\
\text { structures }\end{array}$ & $\begin{array}{l}\text { cytoplasmic/ } \\
\text { apoplastic }\end{array}$ & {$[26,7,43]$} \\
\hline Avr3a & P. infestans & $\begin{array}{l}\text { targets host ubiquitination; AVR effector for } \\
\text { potato protein gene } R 3 a\end{array}$ & cytoplasmic & [44] \\
\hline AvrPiz-t & Magnaporthe oryzae & $\begin{array}{l}\text { targets host ubiquitination; AVR effector for rice } \\
\text { R gene Piz- } t\end{array}$ & cytoplasmic & [46] \\
\hline Slp1 & M. oryzae & chitin oligomers sequestration & apoplastic & {$[53]$} \\
\hline Ecp6 & C. fulvum & chitin oligomers sequestration & apoplastic & {$[51]$} \\
\hline Avr4 & C. fulvum & $\begin{array}{l}\text { protects the fungal cell wall from degradation by } \\
\text { plant chitinases; AVR effector for tomato R gene } \\
C f-4\end{array}$ & apoplastic & {$[51]$} \\
\hline Mg1LysM & Mycosphaerella graminicola & $\begin{array}{l}\text { protects the fungal cell wall from degradation by } \\
\text { plant chitinases }\end{array}$ & apoplastic & {$[52]$} \\
\hline Mg3LysM & M. graminicola & $\begin{array}{l}\text { protect the fungal cell wall from degradation by } \\
\text { plant chitinases; blocks the elicitation of chitin- } \\
\text { induced plant defences }\end{array}$ & apoplastic & {$[52]$} \\
\hline Pep1 & U. maydis & peroxidase inhibitor & apoplastic & {$[56]$} \\
\hline Cmu 1 & U. maydis & targets defence signaling & cytoplasmic & {$[61]$} \\
\hline PSR1 & Phytophthora sp. & targets plant microRNA biosynthesis pathway & cytoplasmic & {$[57]$} \\
\hline Tin2 & U. maydis & targets plant anthocyanin biosynthesis & cytoplasmic & {$[60]$} \\
\hline See1 & U. maydis & $\begin{array}{l}\text { targets SGT1 (Suppressor of G2 allele of skp1) } \\
\text { and it is crucial for tumor progression in leaf } \\
\text { cells. }\end{array}$ & cytoplasmic & [47] \\
\hline Iug6 & M. oryzae & targets both salicylic acid and ethylene pathways & $\begin{array}{l}\text { putative } \\
\text { cytoplasmic }\end{array}$ & {$[22]$} \\
\hline
\end{tabular}


